\title{
The Amoebic Self Scale and GPA are related to the academic procrastination sensu lato
}

\author{
Ernest Bielinis ${ }^{1 *}$ and Lidia Bielinis ${ }^{2}$
}

1 Department of Forestry and Forest Ecology, Faculty of Agriculture and Forestry, University of Warmia and Mazury in Olsztyn, Olsztyn, Poland; ernest.bielinis@uwm.edu.pl

2 Department of Social Pedagogy and Methodology of Educational Research, Faculty of Social Science, University of Warmia and Mazury in Olsztyn, Olsztyn, Poland; lidia.bielinis@uwm.edu.pl

* Correspondence: ernest.bielinis@uwm.edu.pl;

\begin{abstract}
The Amoebic Self Theory is a concept of the social psychology, which postulates that humans have a psychological boundary. As the authors of the concept propose [1], the function of the boundary is to allow psychological separation of one from the others. In this study, we examined how sensitivity to violation of the boundary, measured by an amoebic self scale, is connected with different types of procrastination sensu lato, measured by seven procrastination subscales. Only two of the seven procrastination aspects, i.e. the preference for pressure and outcome satisfaction, were negatively and significantly related to the spatial-symbolic domain of the amoebic self scale. The other purpose of this research was to examine the connection between the students' grade point average (GPA) and scores obtained in the procrastination subscales. Only the non-adaptive aspect of procrastination predicted significantly the GPA. That is an important detail, because pointing out the gap between one's self-opinion and the real, non dependent of the opinion, academic achievement. All these findings were considered in the academic context and consequences of these results were discussed.
\end{abstract}

Keywords: active procrastination; amoebic self-theory; correlation; grade point average; procrastination; procrastination sensu lato

\section{Introduction}

The Amoebic Self Scale (AmSS) is a psychological construct based on a relatively new concept - the Amoebic Self Theory (AST). The AST discloses that psychological behavior of the human beings is metaphorically similar to the behavior of a single cell of a biological organism [2]. According to this concept, people try to approach and incorporate what is perceived as beneficial and rewarding and avoid and protect themselves from what is perceived as harmful or punishing. The AmSS, grounded in this theory, was built as a standardized measure of differences in human's sensitivity to the boundary threat across three domains [1]. The first domain, AmSS-Bodily, refers to a number of largely voluntary, non-violent procedures that reflect a common theme of discomfort related to the thought of having one's bodily envelope breached [1] (e.g., donating blood, receiving blood or organs, receiving injections). In the case of the second domain, AmSS-Social, the participants are presented with a list of hypothetical others who vary in terms of their intimacy and familiarity (from a partner to hated others) and are tutored to cross out any individual(s) around whom, or for whom they would feel uncomfortable performing the specified behavior by a specific item (e.g., asking for help, being in physical contact in a bus). The third domain, measured with a Spatial-Symbolic subscale (AmSSSpatial-Symbolic), consists of the items related to the involuntary loss or modification of identity markers (e.g., an out-of-body experience, changing one's name, the neighborhood by stigmatized institutions) [1].

The other psychological term used in this paper is 'procrastination sensu lato'. Every time, the term is used, it refers to the behavior being a combination of: delaying to work 
on a task and discomfort with the delay ('procrastination') [3] and also non-harmful behavior described as an 'active procrastination' [4]. Both kinds of procrastination may be accurately predicted by self-reporting questionnaires.

Questionnaires analyzed in this work were obtained from a small group of University students. The aim of the analysis was to test the hypothesis that there is a correlation between the different psychological constructs. More specifically, the three domains of AmSS were correlated with seven domains of procrastination sensu lato. It is worth highlighting that the AmSS has its origin in different parts of psychology than the phenomenon of procrastination has, because it is connected with the social psychology, whereas the phenomenon of procrastination refers rather to human being behavior.

It was also interesting to analyze whether different aspects of procrastination are connected with the real academic outcomes, like the obtained GPA. We used scales to measure procrastination in a selected group of students and to confront one's procrastination level with their GPA. The academic achievements are good predictors of the general well-being and further successful employment of a person, thus it seems worthy to find any new of their correlates $[5,6]$.

\section{Materials and Methods}

\subsection{Ethical statement}

This study was ethically reviewed and approved by the Ethical Review Board at the University of Warmia and Mazury in Olsztyn. The number of the ethical statement is 06/2020. All the procedures were performed in this study in accordance with the ethical standards of the Polish Committee of Ethics in Science and with the 1964 Helsinki Declaration's later amendments.

\subsection{Participants}

Undergraduate natural science students ( $n=95,56 \%$ males) from a large Polish university participated voluntarily in this study. The mean age of participants was 21.53 years $(\mathrm{SD}=1.29)$ and all were identified as being European.

\subsection{Measures}

Grade point average (GPA). The participants were asked to complete the questionnaire around two months after they took the last mid-semester exams at the University and were asked to complete their GPA in the questionnaires. The GPA was a numerical calculation of the mean of grades received in courses undertaken in a previous semester. A grade received in each course at the University usually ranged from 3.0 ('weak') to 5.0 ('very good').

Amoebic Self Scale (AmSS). In AmSS-Social, the numbers of cross outs for each item (from 0 to 7) were summed. The AmSS-Bodily and AmSS-Spatial-Symbolic items were answered using a 7-point Likert scale (higher scores = greater discomfort) [1]. We used a Polish adaptation of AmSS (2004) with 22 itmes described by Jaśkiewicz and Drat-Ruszczak [7].

Pure Procrastination Scale (PPS). PPS is a 12-item homogenous construct (Cronbach's $\alpha=.92$ ) that conceptualizes procrastination as a dysfunctional delay [8]. We used the Polish version of PPS $(\alpha=.89)$ adapted from the original English PPS. We also distinguished three independent subscales from the main: decisional procrastination (DP), behavioral procrastination (BP) and non-adaptive procrastination (N-AP). In the cited studies, the DP consisted of 3 items, Cronbach's alpha reliability coefficient was = 
.87 , the BP consisted of 6 items $(\alpha=.82)$ and NAP also consisted of 3 items $(\alpha=.82)$ [9]. Responses were recorded on a 5 -point Likert-type scale.

New Active Procrastination Scale (NAPS). The participants completed another procrastination scale which was NAPS. The scale conceptualized the procrastination differently, as a non-harmful behavior [4]. The NAPS has been reported as a reliable and valid instrument [10]. We used the Polish version adapted from original English NAPS ([11], non-published, the obtained alpha was satisfactory). This multidimensional construct consisted of four subscales, with 4 items in each. The items encompassed a participant's affective preference for: ability to achieve satisfactory outcomes (Outcome Satisfaction subscale, OS), time pressure (Preference for Pressure subscale, PP), cognitive decision to procrastinate (Intentional Decision subscale, ID) and behavioral capacity to meet deadlines (Ability to Meet Deadlines subscale, AMD). Responses were recorded on a 7-point Likert-type scale with varying response anchors (1 - "strongly disagree", 7 - "strongly agree"). In the case of OS, PP and AMD subscales, the items were reverse-scored. A participant's total score was calculated by summing scores for all items, with higher scores indicating a stronger active procrastination.

\subsection{Procedure}

Students were informed that they would be asked to participate in a research study of their behavior and personality. The questionnaires were given to volunteers and were completed anonymously. We used "paper and pencil" research method. Several scales were included in the questionnaire form. To get the result quickly, we calculated the score obtained for each domain and subscale from the response of the individual students. Scores obtained for AmSS subscales, PPS subscales and for NAPS subscales were calculated, respectively.

\section{Results}

A correlation matrix with the number of counts is given in Table 1.

After the correlation was made, the multiple forward regression analysis was applied for the assessment. Subscales of active and passive procrastination were analyzed as predictors of: GPA, SEI and three subscales of Am-SS. Predictions were statistically significant in a positive or negative direction. GPA was significantly predicted only by one from the seven aspects of procrastination sensu lato, i.e. by N-AP $(\triangle \mathrm{R} 2=.06 ; \beta=-.25 ; \mathrm{p}=0.037)$. AmSS-Spatial-Symbolic was significantly predicted by PP $(\triangle \mathrm{R} 2=.17 ; \beta=-.41 ; \mathrm{p}<.001)$. The OS predicted AmS-Spatial-Symbolic also, but it was necessary to apply a different model in forward regression $(\mathrm{R} 2=.14 ; \beta=-.38 ; \mathrm{p}<0.001)$. 
Table 1. Means, SDs and bivariate correlations between GPA, three domains of AmSS and procrastinations.

\begin{tabular}{|c|c|c|c|c|c|c|c|}
\hline & Mean & SD & & GPA & AmSS-Bodily & $\begin{array}{l}\text { AmSS- } \\
\text { Social }\end{array}$ & $\begin{array}{c}\text { AmSS-Spatial- } \\
\text { Symbolic }\end{array}$ \\
\hline \multicolumn{8}{|l|}{ Procrastination } \\
\hline \multirow{2}{*}{ Decisional } & \multirow{2}{*}{2.62} & \multirow{2}{*}{.97} & $r$ & -.07 & -.04 & -.19 & .03 \\
\hline & & & $\mathrm{N}$ & 67 & 85 & 83 & 87 \\
\hline \multirow{2}{*}{ Behavioural } & \multirow{2}{*}{3.19} & \multirow{2}{*}{.91} & $r$ & -.20 & .03 & -.06 & .02 \\
\hline & & & $\mathrm{N}$ & 66 & 83 & 81 & 85 \\
\hline \multirow{2}{*}{ Non-adaptive } & \multirow{2}{*}{2.07} & \multirow{2}{*}{.96} & $r$ & $-.25^{*}$ & -.02 & -.14 & .08 \\
\hline & & & $\mathrm{N}$ & 67 & 85 & 83 & 87 \\
\hline \multicolumn{8}{|l|}{ Active procrastination } \\
\hline \multirow{2}{*}{ Outcome satisfaction } & \multirow{2}{*}{4.22} & \multirow{2}{*}{1.23} & $r$ & .04 & -.10 & -.04 & $-.38^{* * *}$ \\
\hline & & & $\mathrm{N}$ & 66 & 85 & 82 & 87 \\
\hline \multirow{2}{*}{ Preference for pressure } & \multirow{2}{*}{4.04} & \multirow{2}{*}{1.42} & $r$ & .17 & -.04 & -.19 & $-.41^{* * *}$ \\
\hline & & & $\mathrm{N}$ & 67 & 85 & 83 & 87 \\
\hline \multirow{2}{*}{ Intentional decision } & \multirow{2}{*}{3.61} & \multirow{2}{*}{1.21} & $r$ & -.06 & .06 & -.04 & -.17 \\
\hline & & & $\mathrm{N}$ & 66 & 84 & 82 & 86 \\
\hline \multirow{2}{*}{$\begin{array}{l}\text { Ability to meet } \\
\text { deadlines }\end{array}$} & \multirow{2}{*}{5.14} & \multirow{2}{*}{1.13} & $r$ & .13 & .00 & .06 & -.18 \\
\hline & & & $\mathrm{N}$ & 66 & 84 & 82 & 86 \\
\hline
\end{tabular}

Notes: ${ }^{*} p<0.05,{ }^{* * *} p<0.001$

\section{Discussion}

To sum up, only two domains of AmSS were predicted by one of the active procrastination subscales, but none of the domains was predicted by classical procrastination. Each of the AmSS domains was usually differently correlated with the psychological measures [1]. The first, Bodily domain of AmSS is related to hypochondria and depression. A higher score in the second, Social domain of AmSS, is negatively correlated with self-esteem and positively correlated with anxiety. The third, Spatial-Symbolic domain, is in relation to feelings of disgust, fear, and to such behaviors as: attacking others, cheating, exploitation of others $[1,2,7]$. The AmSS-Social and AmSS-Spatial-Symbolic were also correlated with engulfing the self scale, which is connected with self-expansion motivation and with the dark triad [2]. In our study, a negative correlation was found between the PP, OS and the AmSS-Spatial-Symbolic, and reflections about these relations are not obvious. We suppose that participants obtaining a higher AmSS-Spatial-Symbolic scores have stronger motivation to do things (this is one explanation) or have stronger fear/disgust of, e.g. 'being accused of being lazy', 'late', etc., and, respectively, fear or disgust motivated one's to avoid procrastination (this is the second explanation). The occurrence of one's lower threshold of satisfaction is also a good explanation. Distinguishing which of the three possibilities is likely, needs to be further investigated.

Noteworthy is that only one of the seven different aspects of active and passive procrastination (the Non-AP), had a significant effect on participants' lives. Only this parameter predicted the lower academic scores (a lower GPA). The questionnaires containing only the Non-AP subscale; with 3-question items: 1) "I don't get things done on time", 2) "I am not very good at meeting deadlines", 3) "Putting things off till the last minute has cost me money in the past"; might help identifying the participants' problems with negative effects of procrastination. Nevertheless, if a surveyed participant obtains high 
scores in Non-AP and has low exam scores, it would be deemed reasonable to attempt any kind of therapy that seems to be helpful for participants in obtaining their life goals and improving their life satisfaction, e.g. Cognitive Behaviour Therapy [12].

For further improvements in the study on the effect of a relation between N-AP and GPA, we recommend applying the Big Five Personality Inventory [13]. We suppose that a GPA might have some other kind of connection with the personality traits than with $\mathrm{N}-\mathrm{AP}$, and that the differences should be examined with aspects of active and passive procrastination scales.

\section{Conclusions}

We can conclude that interesting results may be achieved from comparing the two different scales, and that it is a big step to further studies in the area of common parts of human behavior and social psychology. The negative correlation between the active procrastination and the AmSS-Spatial-Symbolic is a significant fact indicating the reason of individual human behavior preferences and also suggesting that individuals characterized with a high AmSS-Spatial-Symbolic might not take motivation of themselves by the pressure of time. They chose different ways to motivate themselves and face low outcome satisfaction. In addition, this study revealed that only N-AP had a significant effect upon the GPA. It means that only this part of procrastination might be significant in predicting the academic outcomes.

Author Contributions: Conceptualization, E.B. and L.B.; methodology, E.B. and L.B.; software, E.B. and L.B.; validation, E.B. and L.B.; formal analysis, E.B. and L.B.; investigation, E.B. and L.B.; resources, E.B. and L.B.; data curation, E.B. and L.B.; writing-original draft preparation, E.B. and L.B.; writing - review and editing, E.B. and L.B.; visualization, E.B. and L.B.; supervision, E.B. and L.B.; project administration, E.B. and L.B.; funding acquisition, E.B. and L.B.;.

All authors have read and agreed to the published version of the manuscript.

Funding: This research received no external funding

Conflicts of Interest: The authors declare no conflict of interest

\section{References}

1. Burris, C.T.; Rempel, J.K. "It's the end of the world as we know it": threat and the spatial-symbolic self. Journal of Personality and Social Psychology 2004, 86, 1-19.

2. Burris, C.T., Rempel, J.K., Munteanu, A.R., Therrien, P.A. More, More, More The Dark Side of Self-Expansion Motivation. Personality and Social Psychology Bulletin 2013, 39, 578-595.

3. Krause, K., Freund, A.M. Delay or procrastination-A comparison of self-report and behavioral measures of procrastination and their impact on affective well-being. Personality and Individual Differences 2014, 63, 75-80.

4. Choi, J.N., Moran, S.V. Why not procrastinate? Development and validation of a new active procrastination scale. The Journal of Social Psychology 2009, 149, 195-212.

5. Lepp, A.; Barkley J.E.; Karpinski, A.C. The relationship between cell phone use, academic performance, anxiety, and satisfaction with life in college students. Computers in Human Behavior 2014, 31, 343-350.

6. Sulastri, A.; Handoko, M; Janssens, J. M. A. M. Grade point average and biographical data in personal resumes: predictors of finding employment. International Journal of Adolescence and Youth 2015, 20, 306-316.

7. Drat-Ruszczak, K.; Jaśkiewicz, M.. Skala Wrażliwości na Naruszenie Granic Ja (SNaG): polska adaptacja Skali Amebowego Ja (Amoebic Self Scale) C. Burrisa i J. Rempela [Self boundaries sensitivity scale: Polish adaptation of Burris and Rempel's Amoebic Self Scale]. Psychologia Społeczna [Social Psychology] 2011, 18, 262-266.

8. Steel, P. Arousal, avoidant and decisional procrastinators: Do they exist? Personality and Individual Differences 2010, 48, 926-934.

9. Stępień, M.; Topolewska, E. Style tożsamości w ujęciu Berzonsky'ego a prokrastynacja [Berzonsky's model of identity styles and procrastination]. In: Topolewska, E., Drop, E. Skrzek, S. (Eds.), Młoda Psychologia [Young Psychology] 2014, volume 2, Warsaw, LiberiLibri.

10. Demeter, D.V.; Davis, S.E. Procrastination as a Tool: Exploring Unconventional Components of Academic Success. Creative Education 2013, 7, 144.

11. Stępień, M.; Cieciuch, J. Polish version of New Active Procrastination Scale (NAPS) 2020, non-published. 
12. Rozental, A.; Carlbring, P. Internet-based cognitive behavior therapy for procrastination: study protocol for a randomized controlled trial. JMIR Research Protocols 2013, 2, e46. http://dx.doi.org/10.2196/resprot.2801

13. Furnham, A.; Moutafi, J.; Chamorro-Premuzic, T. Personality and intelligence: Gender, the Big Five, self-estimated and psychometric intelligence. International Journal of Selection and Assessment 2005, 131, 11-24. 